\title{
Estratégias mediadoras no ambiente virtual
}

\author{
Mediating strategies on the virtual \\ environment
}

Simone Correia Tostes*

Centro de Estudos de Pessoal e Forte Duque de Caxias (CEP/FDC)

Rio de Janeiro - Rio de Janeiro / Brasil

\begin{abstract}
RESUMO: Neste trabalho, tentamos identificar estratégias positivas de interação professor-aluno num curso a distância. Lançamos mão da microanálise etnográfica para investigar o discurso do professor, como ele acredita que a linguagem ajuda os alunos e como os alunos pensam que o discurso do professor contribui para obter sucesso num curso online. A apuração dos dados coletados e do questionário evidenciaram um alinhamento entre as declaraçôes dos alunos e as do professor. Discentes e docente apontam como atributos principais do professor para a aprendizagem em ambientes virtuais a presença ativa, o relacionamento afetivo, a atenção e a dedicação. Os resultados desta pesquisa oferecem subsídios para a formação inicial e continuada de professores com a finalidade de obterem-se melhores resultados nos esforços empreendidos para mediar o desenvolvimento da aprendizagem.
\end{abstract}

PALAVRAS-CHAVE: interação, ambiente virtual, discurso, professor.

ABSTRACT: In this research we have tried to grasp the strategies that work on the teacher-student interaction on a distance education course. We have applied micro-ethnographic analysis to investigate the teacher's discourse, how he believes the way he uses language helps students and how students think the teacher's discourse helps them succeed in an online course. The data collected has shown that there is agreement between the students' and the teacher's opinions. They both point out the participation, affection, attention, and dedication on the teacher's part as the main features that make learning easier. The results obtained in this research offer some foundation for the initial or continued preparation of teachers in order to reach the best results in the efforts to mediate the development of learning.

KEYWORDS: interaction, virtual environment, discourse, teacher.

*stostes@gmail.com 


\section{Breve histórico da EAD}

Existem algumas tentativas de se trilhar o ponto de partida do ensino a distância, mas não há consenso sobre quando foi seu início. As versões mais aceitas são a de seu advento com a invenção da impressão de caracteres por Guttenberg e a que atribui sua origem às cartas de São Paulo aos filisteus. No Brasil, ficou conhecida por meio dos cursos por correspondência, principalmente os do Instituto Universal Brasileiro, que oferece formação em diversos tipos de cursos técnicos. Com a evolução tecnológica, existem cada vez mais recursos especialmente voltados para a $\mathrm{EAD}$; várias plataformas foram criadas, e um sem número de tecnologias foi inventado para atender às necessidades específicas de cada curso.

Existem três gerações na EAD: (1) o ensino por correspondência, caracterizado pelo uso de material impresso; (2) a teleducação, que adicionou o uso de meios radiofônicos e televisivos; e (3) os ambientes interativos, que permitem o acesso à educação sem restrição de tempo para acesso. Esses ambientes permitem interações síncronas ou assíncronas. Cada vez mais, as instituições tentam se modernizar e oferecer tecnologias mais avançadas que permitem aproximar alunos e professores nos diversos tipos de ambientes virtuais de aprendizagem (AVA). Existem diversas plataformas capazes de abrigar cursos a distância, sendo a Plataforma Moodle uma das mais conhecidas e utilizadas, pois possibilita o uso de ferramentas diversificadas que transformam o espaço virtual em sala de aula.

Atualmente vista como tábua de salvação em algumas situações em que o aluno não dispóe de tempo para se deslocar para instituiçóes de ensino para dar prosseguimento a seus estudos, a quantidade e a variedade de oferta de cursos a distância vêm aumentando sobremaneira na última década. Esses cursos normalmente apresentam como vantagem principal o fato de o aluno ter flexibilidade para estudar e cumprir suas tarefas de acordo com sua disponibilidade. As escolas não "fecham". Em vez de se adaptar a uma grade horária e a calendários rígidos que exigem sua presença física em diversos momentos do processo, o aluno distribui os conteúdos e atividades previstas num curso de acordo com seu cronograma particular.

Essa sensação de liberdade em que o aluno se vê como gerente do processo de aprendizagem apresenta vantagens e desvantagens. As vantagens são as anunciadas pelas instituições que oferecem tais cursos $-\mathrm{o}$ aluno tem total autonomia para gerir seu ritmo e suas atividades de estudo. As desvantagens residem no fato de que nem todos os alunos têm o perfil necessário para 
administrar suas próprias atividades. Em poucas palavras, essa aparente "liberdade" pode ser o calcanhar de Aquiles da EAD, podendo gerar comportamentos de procrastinação, que acabam sendo extremamente danosos para a aprendizagem. Em vez de se organizar e distribuir as tarefas ao longo do curso, por exemplo, o aluno da EAD pode se dedicar aos estudos apenas em véspera de prova ou para cumprir o calendário de entrega de tarefas.

Outro sentimento bastante comum no aluno é a sensação de solidão inerente ao processo. Acostumado a ter a presença física do professor e à interação com pessoas de "carne e osso", um aluno pode estranhar as interaçóes assíncronas que os fóruns e as salas de discussão possibilitam. Apenas para citar um exemplo, uma pergunta feita não é mais respondida imediatamente pelo interlocutor como em uma conversa natural e espontânea. Espera-se que um bom professor / mediador responda a questionamentos e dúvidas de seus alunos em até 24 horas. Isso pode amplificar a sensação de solidão do aluno que, aparentemente, está "falando sozinho".

Um terceiro elemento bastante diferenciado na EAD é a supressão do conceito de educação bancária (FREIRE, 2005). Assim, em vez de ter aulas "cospe giz", o aluno é todo o tempo convidado a interagir e participar. Uma dúvida não é respondida num bate-bola direto com o professor / mediador. Em vez disso, é esperada a contribuição e participação dos demais colegas de turma, que sugerem, opinam, corrigem e até modificam o conteúdo, com a chancela do professor / mediador.

Tudo isso requer um realinhamento de funções e outra forma de se entender a educação. Em vez de um professor no tablado, com uma mesa maior e o poder de alocação dos turnos de fala, com alunos alinhados escutando e anotando informações, há uma redefinição na geografia da sala de aula. Nem todos estão presentes ao mesmo tempo; se estiverem presentes ao mesmo tempo, estão em diferentes lugares, o professor passa a ser um interlocutor e direcionador das discussóes. Pode-se dizer que o professor / mediador simplesmente orienta os trabalhos. Ele passa de detentor do saber sistematizado a participante na coconstrução do conhecimento.

Percebe-se que ainda predomina a falsa crença de que a EAD implica menos custos do que a educação presencial. Entretanto, o aluno somente se sentirá efetivamente acolhido e atendido se dispuser de infraestrutura e suporte de qualidade, e isso requer uma razão proporcional entre professores e alunos (quantidade), assim como exige profissionais bem preparados para atender às demandas da população discente que, na maioria das vezes, não terá oportunidade de conhecer pessoalmente (qualidade). 
Entre todas essas características, o discurso configura-se como a principal ferramenta da EAD. O manejo de classe nessa nova modalidade pode ser entendido como capacidade comunicativa. Ao mesmo tempo, deve tentar aproximar alunos distantes, mantendo os níveis de motivação para a aprendizagem. Isso exige o domínio de estratégias de comunicação que permitam que o processo se desenvolva satisfatoriamente. Não basta ter o conhecimento técnico dos conteúdos: o professor deve estar preparado para o manejo do discurso na EAD.

\section{Diálogo na EAD}

Há sugestões de que o trabalho em EAD deve encorajar a parceria entre professor e alunos. Conforme apontam Dotta e Giordan (2008), isso implica uma transição da lógica de distribuição para a lógica da comunicação. $\mathrm{O}$ professor passa de informador a mediador, direcionando os debates e encorajando a participação na sala de aula. O direcionamento dos debates é realizado pela problematização. Conforme apontou Freire (2005), a problematização possibilita a análise crítica da realidade.

Note-se que na EAD a coparticipação abre caminho para a construção do conhecimento. Wells (1999) vai ao encontro dessa concepção de educação ao formular o conceito de debate dialógico, que fomenta a construção colaborativa do conhecimento. Isso reforça a ideia de buscar a significação dos significados proposta por Freire.

Assumimos o conceito de diálogo conforme proposto por Bakhtin (1978), que visualiza esse fenômeno na coocorrência de diversas vozes em cada enunciado de fala oral ou escrita. Isso significa que cada enunciado é polifônico, constituído de falas que o antecederam e o influenciaram. Dentro desse esquema, ao verbalizar um pensamento, cada interlocutor necessariamente interagiu e refletiu sobre outros pensamentos. $\mathrm{Na} E A D$, é o diálogo que permite que o conhecimento seja construído, isto é, que se compreenda a "significação dos significados" referida anteriormente.

Mortimer e Scott (2002) categorizaram quatro tipos de abordagem comunicativa entre professores e alunos: o discurso dialógico ou de autoridade e o discurso interativo ou não interativo. Dotta e Giordan (2006) apontam que o discurso de autoridade limita o fluxo do diálogo. Assim, é desejável que as atividades educacionais dessa nova organização da sala de aula possibilitem trocas interativas simétricas entre alunos e professores. Giordan (2006) sintetiza esse novo conceito na educação: 
Em situações de educação a distância, o diálogo interativo ocupa papel central na aprendizagem, pois contribui para a (re)elaboração de significados gerados a partir das múltiplas vozes referidas em cada enunciação. A aprendizagem dialógica é um processo que promove o reposicionamento do sujeito no horizonte conceitual do outro e a apropriação de gêneros de discurso e atitudes científicas.

Dotta e Giordan (2007) destacam a importância da formação de profissionais de educação que transcenda o mero conhecimento técnicoprofissional dos conteúdos. Essa formação deve incitar o desenvolvimento da capacidade comunicativa, responsiva e de alteridade nas interações a fim de promover a aprendizagem dialógica. Eles também destacam a complexidade da comunicação em serviços de tutoria online, pois implica traduzir para a linguagem escrita a entonação, os gestos, a sonoridade e a expressão facial da linguagem falada.

A diferença apontada por Vygotsky (1996) entre o discurso escrito e o oral é de fundamental importância para entendermos a complexidade da utilização da linguagem escrita, que exige dupla abstração - a do aspecto sonoro da linguagem e a do interlocutor imaginário. Outro aspecto que denota a complexidade da linguagem escrita é a representação do pensamento obedecendo a um sistema arbitrário e organizado - isto é, a transferência da linguagem interior para o exterior.

Davis e Brewer (1997) salientam que, apesar de ter uma dinâmica que a distingue da língua falada, marcada por interrupções e sobreposições, a linguagem virtual se assemelha a processos de interação face a face na medida que é permeada de repetições, referência direta e interrupções no fluxo discursivo.

Garcia Aretio (2001) afirma que a competência comunicativa consiste em habilidade de importância fundamental na relação entre professor / mediador e aluno. Ela está relacionada à capacidade de interagir individualmente com cada aluno, incentivando sua participação com o grupo de forma a evitar o sentimento de solidão e a consequente desistência do curso. Garcia Aretio (id.) também institui três funções do mediador: (1) uma função orientadora, que se concentra em aspectos da área afetiva; (2) uma função acadêmica, relacionada ao aspecto cognoscitivo; e (3) uma funçáo institucional, relacionada aos aspectos que envolvem professor e aluno ligados a uma determinada instituição de ensino. 


\section{A teoria da polidez: as quatro faces da interação}

A Teoria da Polidez, de Brown e Levinson (1987), sistematiza uma série de estratégias comunicativas que afastam ou aproximam o falante e o ouvinte nas interaçōes. Para compreender a teoria, é imprescindível ter em mente as quatro faces envolvidas em qualquer tipo de interação falante-ouvinte: (1) a face positiva do falante; (2) a face negativa do falante; (3) a face positiva do ouvinte; e (4) a face negativa do ouvinte.

A face positiva pode ser compreendida como uma versão de nós mesmos que deixamos exposta em nossos grupos sociais; refere-se a tudo o que é aprovado e valorizado. Já a face negativa consiste em tudo o que não queremos que o nosso interlocutor veja ou perceba, pois refere-se ao nosso próprio território - aquilo que não mostramos a ninguém. Usando a metáfora da fotografia, podemos associar a face positiva à foto impressa (vistosa, colorida, brilhante) e a face negativa corresponderia ao negativo da foto (sem cor, sem brilho, difícil de se enxergar).

Brown e Levinson (id.) também relacionam várias estratégias de polidez de que fazemos uso em nossas interações diárias. São mecanismos que nos levam a proteger nossa face, bem como a do nosso interlocutor:

- perceba o outro; mostre-se interessado pelos desejos e necessidades do outro;

- exagere o interesse, a aprovação e a simpatia pelo outro;

- intensifique o interesse pelo outro;

- use marcas de identidade de grupo;

- procure acordo;

- evite desacordo;

- pressuponha, declare pontos em comum;

- faça piadas;

- explicite e pressuponha os conhecimentos sobre os desejos do outro;

- ofereça, prometa;

- seja otimista;

- inclua o ouvinte e o falante na atividade;

- dê ou peça razóes;

- simule ou explicite reciprocidade;

- dê presentes. 
São as estratégias de polidez positiva que possibilitam a aproximação e a solidariedade. No ambiente online, convencionou-se chamar de e-politeness (GRAHAN, 2007) as regras de polidez que tentam preservar a face do falante e de seu interlocutor nas trocas e interações no espaço virtual.

\section{Motivação e aprendizagem}

A motivação consiste na predisposição intrínseca para realizar alguma tarefa. Segundo Gagné (1985), é condição indispensável para a aprendizagem. Tapia e Fita (1999) sintetizam as quatro grandes classes da motivação para a aprendizagem:

1. Motivação intrínseca ou motivação relacionada com a matéria - tem origem na identificação pessoal do aluno com os conteúdos de determinada matéria. Tome-se como exemplo o aluno que não tem sucesso na aprendizagem de outros assuntos, mas, quando chega a aula de matemática, demonstra interesse pelo conteúdo apresentado, que lhe possibilita a aquisição de novos conteúdos, e a aprendizagem resultante contrasta com os demais resultados.

2. Motivação relacionada com a autoestima - está intimamente ligada ao aspecto afetivo do indivíduo. Por exemplo, um aluno se sente mais valorizado em seu autoconceito na mesma medida que obtém êxitos e sucessos nas tarefas de aprendizagem, adquirindo autoconfiança, que o alicerçarão para dar prosseguimento às demais atividades de estudo. $\mathrm{O}$ desenvolvimento dessa motivação é essencial para a aprendizagem: alunos com alto nível de autoestima aprendem com mais facilidade. Esse tipo de motivação pode causar uma dependência externa extremamente danosa para as atividades que levam à aprendizagem. $\mathrm{O}$ elogio pode se tornar cada vez mais raro, pois torna-se esperado que um determinado aluno obtenha bom desempenho, e isso pode afetar ou anular a motivação.

3. Motivação relacionada à valorização social - associada à satisfação afetiva de aceitação pelos outros. Como exemplo, podemos imaginar aquele aluno que só se sente bem quando é elogiado e valorizado por seu professor e reconhecido pelo grupo.

4. Motivação relacionada à recompensa - refere-se ao comportamento que vislumbra a conquista de uma vantagem ou prêmio ao final da aprendizagem. Um aluno que estuda para passar de ano, pensando no prêmio da viagem a Disney no fim do ano, enquadra-se nessa categoria. O ponto negativo situase no fato de que, retirada a recompensa, o esforço diminui ou se anula. 
Estudos sobre motivação estabelecem uma correlação entre características pessoais e contextos de aprendizagem (TAPIA; FITA, 1999). A interação entre o professor e seus alunos é apontada como um dos aspectos essenciais da motivação, assim como o começo da aula, a organização das atividades e a avaliação da aprendizagem. Segundo esses autores, esses momentos podem interferir, reforçar ou anular os padrões motivacionais para a aprendizagem. Essas decisões dependem da atuação do professor. Merino e Tapia (1990) destacam as mensagens do professor para seus alunos antes, durante e após tarefas escolares como um dos fatores contextuais que mais influenciam a motivação dos alunos, facilitando ou dificultando a aprendizagem.

Tapia e Fita (op. cit.) destacam o professor como figura chave na motivação dos alunos:

Se um professor não está motivado, se não exerce de forma satisfatória sua profissão, é muito difícil que seja capaz de comunicar a seus alunos entusiasmo, interesse pelas tarefas escolares; é, definitivamente, muito difícil que seja capaz de motivá-los (p. 88).

Tapia e Fita (op. cit.) destacam ainda que, em sua maneira de atuar, o professor comunica não somente conteúdos mas também maneira de raciocinar, estilo cognitivo, personalidade, atitudes, valores. Em suma, a própria figura do professor pode ser uma ferramenta de motivação importantíssima, pois é a partir do relacionamento com nossos alunos que estabelecemos uma ponte para a confiança e o aumento da atenção, tão necessários para a aprendizagem. Nenhuma tecnologia pode substituir a atuação do professor, pois esta permite o estabelecimento de canais de comunicação pessoal por meio do contato pessoal, da escuta e da ajuda. Barbosa (2010) sintetiza o papel imprescindível do professor / mediador na EAD: "Sem o tutor não será possível a interação, o envolvimento e, consequentemente, a permanência do aluno no curso" (p. 44).

É importante salientar que os autores advertem sobre a necessidade do conhecimento técnico do assunto que se ministra. De nada adianta ter uma boa competência comunicativa (HYMES, 1971) para interagir com seus alunos se o professor não domina o conteúdo que leciona.

\section{Objeto de estudo}

O objeto de estudo desta pesquisa é o discurso do docente num curso de extensão em tutoria a distância. Antes do início do curso, foi realizada uma reunião preparatória com duração de duas jornadas vespertinas, a fim de 
orientar os alunos sobre a condução do processo pela instituição de ensino. $\mathrm{O}$ curso foi oferecido gratuitamente em parceria com duas instituições de ensino superior - uma federal e outra particular. A empresa particular ofereceu o curso gratuitamente aos professores da instituição federal interessados, como estratégia mercadológica de captar mais mão de obra para atuar como mediadores em seus cursos de EAD. Aos professores da instituição federal foi franqueada a inscrição no curso, a fim de lhes permitir contato com novas tecnologias de informação e comunicação, bem como para contribuir com o processo de modernização da EAD naquela instituição de ensino. Há muitos anos inserida na EAD, essa instituição federal iniciou um movimento para tentar modernizar e atualizar seus processos, ainda caracterizados por procedimentos da primeira geração da EAD. Depois de quase 30 anos, seus cursos a distância ainda se enquadram na categoria de ensino por correspondência.

A turma considerada era composta de 22 alunos. A maioria do público discente constituía-se de professores efetivos ou prestadores de serviço da instituição de ensino federal. O curso teve duração de quatro meses. Durante esse período, foram realizadas duas reuniões online através da sala de bate-papo da plataforma da instituição de ensino. Foram as únicas oportunidades síncronas do curso. Os demais contatos entre os participantes foram realizados através da sala de discussōes ou através de mensagens particulares, utilizando o correio eletrônico da plataforma.

O professor / mediador entrava no ambiente virtual de aprendizagem com uma frequência de pelo menos duas vezes ao dia. Nessas oportunidades, respondia às perguntas dos alunos, elogiava a contribuição dos colegas, participava e / ou direcionava as discussões de acordo com o cronograma de trabalho do curso.

Nas duas jornadas de preparação para o curso, foi possível compreender que o professor / mediador tem bem pouca liberdade para transcender a relação de conteúdos como está estabelecida no AVA. Ficou evidente que essa é uma orientação filosófica forte dentro dessa instituição de ensino, que permite pouca ou nenhuma flexibilidade no manejo dos conteúdos. Para ratificar essa observação, é relevante apontar a incapacidade de o professor resolver por meios próprios algumas questões técnicas que ocorreram ao longo do curso. Por vezes, a turma esperou até 48 horas para que um problema fosse sanado pelo pessoal do suporte.

Essa falta de liberdade para criar e escolher o melhor método de trabalho com os conteúdos do curso assemelha-se a uma camisa de força para o 
profissional entusiasmado e criativo em sala de aula. Por diversas vezes, percebi que o professor / tutor era limitado por essa imposição da instituição de ensino onde o curso foi ofertado.

Por outro lado, parece haver liberdade total no trato com os alunos. De início, causaram-me estranheza expressões como "turma linda"; "debate maravilhoso" etc. Aos poucos, fui verificando que essa maneira de se dirigir aos alunos aproximava e atenuava a dificuldade intrínseca na realização de um curso a distância. Além disso, essas estratégias substituíam muitas vezes um olhar, um sorriso, um sinal de aprovação, que são constantes na sala de aula presencial. Assim, foi possível observar como pesquisadora participante as estratégias de que esse professor fez uso.

Ao longo do curso, o professor demonstrou extrema competência comunicativa no atendimento oportuno às solicitaçóes e dúvidas dos alunos bem como na realização de comentários. É sabido que o professor em estudo é altamente conceituado na instituição de ensino superior onde realiza suas atividades de tutoria. Portanto, é interessante verificar os motivos por que sua prática pedagógica é eficiente do ponto de vista da análise do discurso. Ao mesmo tempo, procuramos comparar o discurso de que o professor efetivamente lança mão e a explicação do sucesso atribuído pelos alunos e pelo próprio professor.

Nem todos os alunos conseguiram concluir o curso até o final. Além disso, as contribuições nos fóruns de discussão e na sala de aula foram diminuindo à medida que as unidades didáticas avançavam. Vários alunos que no início entravam na sala de discussão, liam e comentavam as opiniões dos colegas ao longo do curso apenas cumpriram burocraticamente o ritual de elaboração e entrega das tarefas de acordo com o calendário preestabelecido.

Como aluna do curso e por trabalhar na mesma instituição dos demais alunos, participei de várias conversas informais sobre o andamento do curso. Após as primeiras semanas, notei um desinteresse crescente pelos conteúdos apresentados no AVA e ouvi críticas a respeito da animação elaborada para acompanhar o material da homepage, da desatualização dos conteúdos, da atuação limitada do tutor, que apenas repetia ipsis literis o conteúdo como esse se apresentava na plataforma.

A parte prática configurou-se como uma área sensível do curso oferecido. Por diversas vezes, verificou-se um descompasso entre o pedido das tarefas e os meios disponibilizados para realizá-las. Por exemplo, algumas atividades requeriam que os alunos professores entrassem na plataforma para avaliar os trabalhos de outros alunos ou mover um conteúdo de um lugar para 
outro. Entretanto, somente após algumas tentativas verificou-se que, como alunos, não estávamos credenciados a realizar qualquer tipo de modificação na sala de aula. Em contato com o suporte técnico, o professor conseguiu sanar esse problema, mas isso foi motivo de pesadas críticas fora do AVA. Comentava-se sobre a aparente incapacidade técnica do professor / mediador para sanar problemas.

O interesse em realizar a pesquisa nesse ambiente virtual de aprendizagem reside na necessidade de compreender o que caracteriza o discurso eficaz em EAD. Verifiquei nas trocas de mensagens entre o professor e seus alunos nos fóruns de discussão a presença de um estilo próprio e peculiar de orientação de alunos. Nessas mensagens do professor, percebi que a afetividade consistia um traço marcante desse professor / mediador e acreditei que isso fosse um ponto altamente positivo e facilitador das interaçóes e motivador da participação e aprendizagem dos alunos.

Spencer-Oatey e Ruhi (2007) apontaram que, apesar de constituir um vasto campo de pesquisa em pleno crescimento, as pesquisas sobre assuntos de identidade, face e polidez são escassas até o momento.

\section{Metodologia: a microanálise etnográfica}

A metodologia de estudo adotada nesta pesquisa pretendeu exercitar princípios da microanálise etnográfica. Segundo Erickson (1988), esse modelo de análise busca verificar aspectos do significado não imediatamente acessíveis em dados da memória consciente dos informantes.

Conforme salienta esse autor, a etnografia considera essencial para a pesquisa "a fala que ocorre naturalmente, considerada como um modo de atividade social que é situado, bem como a cena imediata da vida social local, na qual a fala em si ocorreu."

O autor destaca o foco no particular como traço primordial da etnografia:

A descrição etnográfica na pesquisa sociolinguística tem como um interesse central os detalhes do desempenho situado, tal como ocorre naturalmente nas interações da vida diária. A etnografia documenta o que as pessoas realmente fazem ao falar e descreve, de modo muito específico, a fala e as situações de uso (p. 1084?).

O principal método de coleta de dados da etnografia é a observação participante, segundo a qual o pesquisador integra e observa o evento estudado. 
Esse método é comumente combinado com gravações em áudio e / ou vídeo e entrevistas informais. O presente trabalho não teve como objeto de análise gravações em áudio e vídeo, pois não dispusemos desses recursos no curso, mas tão somente as interaçôes professor-aluno, que compuseram o diário de campo do observador participante.

Atendemos ao princípio da triangulação de dados da pesquisa etnográfica (cujo objetivo é apresentar evidências a partir do ponto de vista dos participantes) ao realizar a aplicação de questionários aos alunos e ao professor, que apresentaram suas impressóes sobre pontos diversos de sua participação no AVA.

Em síntese, a metodologia de microanálise etnográfica permitiu-nos uma compreensão integrada de linguagem e socialização daquele grupo específico.

\section{Coleta de dados}

\section{Sala de aula: Discussões gerais}

Os dados para análise foram coletados do ambiente virtual de aprendizagem de um curso para formação de professores tutores a distância. Num período de quatro meses, foram reunidas todas as interaçóes entre o professor-tutor e seus alunos para posterior análise. Todas as falas que estudamos nesta pesquisa realizaram-se no ambiente de discussóes gerais da sala de aula não só por se tratar do local em que os conteúdos eram apresentados, bem como por se constituir no espaço em que comentários, dúvidas e perguntas eram postados, requerendo uma resposta, comentário ou avaliação do professor.

Foram consideradas as ocorrências de fala do professor em 4 dos 5 módulos didáticos. $\mathrm{O}$ módulo 5 foi descartado de nossa análise por ter sido o momento de prática no AVA. Nessa oportunidade, foram postadas na sala de discussões somente dúvidas relacionadas a como realizar tarefas no ambiente e não se observou quase nenhum comentário sobre os assuntos abordados naquele módulo. Dessa forma, consideramos a amostra dos 4 módulos iniciais como suficiente para caracterizar a participação e a atuação do professor / mediador na sala de aula. 


\section{Aplicação de questionários}

Além da análise das interações entre o professor e os alunos na sala de aula virtual e nos fóruns de discussão, procedeu-se à aplicação de dois tipos de questionários - um direcionado aos alunos, e o outro, ao professor. Com a aplicação desses questionários foi possível ter acesso às opiniōes do público discente sobre os pontos positivos e negativos dessa sala de aula do AVA, assim como sobre o autoconhecimento da prática pedagógica do professor / mediador.

Os questionários foram enviados através de correio eletrônico a cada um dos participantes do curso, num total de 21 questionários. Desse total, obtiveram-se respostas a 8 questionários. Os questionários foram acompanhados de uma mensagem que pedia a colaboração de cada um dos participantes para respondê-los. A esse público, foi informado apenas que a pesquisa tinha por objetivo investigar estratégias, situações e atividades que têm efeito positivo e / ou negativo em EAD. O questionário era composto de 5 perguntas - duas do tipo sim-não e três abertas. O questionário apurou a visão do aluno com relação aos seguintes aspectos: (a) se considerou a atuação do professor / mediador satisfatória ou insatisfatória; (b) se a atuação do professor influenciou sua motivação durante o curso; e (c) que estratégias influenciaram sua participação positiva ou negativamente.

O questionário para o professor foi aplicado individualmente, em etapa posterior, e apresentava 7 perguntas, três das quais do tipo sim-não e quatro do tipo aberta. O questionário era sobre (a) experiência profissional do professor, (b) avaliação do seu trabalho, (c) autoavaliação, (d) estratégias que dão melhor resultados, (e) cuidados que se deve ter com a linguagem e (f) fatores que podem influenciar negativamente seu trabalho.

A aplicação dos questionários serviu para realizar a triangulação dos dados coletados e analisados, isto é, para comparar e contrastar o discurso do professor, a opinião dos alunos e o autoconhecimento / autoanálise do professor sobre sua atuação em sala de aula. Verificamos que muitos pontos apontados pelos alunos e pelo professor coincidiram com as ocorrências de fala do professor, bem como com suas respostas ao questionário.

\section{Análise dos dados}

A análise dos dados coletados foi realizada em dois momentos distintos: o levantamento e categorização das ocorrências de fala do professor / mediador e a tabulação dos questionários. 


\section{Levantamento das ocorrências}

Todas as ocorrências de fala do professor foram analisadas e classificadas à luz das estratégias de polidez positiva da Teoria de Brown e Levinson (1987), mencionada anteriormente. Para facilitar nossa análise, distribuímos as ocorrências dentre as estratégias elencadas por esses autores em 3 grandes grupos.

\section{Grupo A: Exagere o interesse, a aprovação e a simpatia pelo outro}

Nessa grande categoria, foram listadas todas as ocorrências que visavam a criar um ambiente de afetividade, valorização, identificação e aprovação. Dos três tipos, esse foi o mais recorrente no discurso do professor. Trata-se de uma estratégia pedagógica que permite a aproximação professor-aluno mesmo a distância. Ela permite o preenchimento do espaço virtual com afetividade e sensibilidade, aparentemente inesperados dado o afastamento geográfico dos participantes das interações.

Caracteriza-se pelo uso exacerbado de adjetivos, por elogios e pela valorização das contribuições dos alunos, como evidenciam as ocorrências 1 , 2 e 3 a seguir.

\section{Ocorrência 1:}

Não élindo ver o conhecimento sendo construído assim coletivamente???

\section{Ocorrência 2:}

Essa é a turma mais linda que já tive aqui no [... e e não pensem que falo isso para todas, não...

Ocorrência 3:

Parabéns pelas considerações relevantes e tão bem construidas... sei que não poderia ser diferente dado o nivel da turma... mas fico deveras contagiado...

O professor também utiliza o discurso e a participação dos alunos para "costurar" suas contribuiçóes. Ao reconhecer e valorizar o discurso do outro, ocorre um sentimento de identidade no grupo, que fica mais coeso, sólido e fortalecido. Observem-se dois exemplos desse tipo de "costura" feito pelo professor / mediador.

Ocorrência 4:

A consideração do R. é muito relevante... a questão da Educação a distância, das mídias, do hipertexto tem sido alvo de muitas pesquisas no campo educacional... 


\section{Ocorrência 5:}

Concordo com a S. e com o D. Precisamos estar sempre atentos para que não sejamos inconvenientes em alguma brincadeira. Para nós pode ser bastante normal, entretanto nosso aluno pode não compreender da mesma forma, não é mesmo?

\section{Ocorrência 6:}

O tema levantado pela $H$. é muito sério... na verdade, o fantasma que assombra a EAD... O professor-tutor precisa estar atento às variaçôes da turma è̀s peculiaridades dos alunos (o vídeo que a L mostrou é a realidade... conhecemos nossos alunos?).

\section{Grupo B: Procure acordo}

Neste grupo foram classificadas todas as contribuições e colocações do professor que visavam a evitar o confronto ou qualquer situação de ameaça à face de seus interlocutores. Para compreendermos o uso da estratégia, transcrevemos a seguir uma sequência em que ela se passou.

\section{Ocorrência 7:}

[ALUNO]: Prezado Professor,

Acredito que o caminho para acesso do formulário de pró-atividade seja o seguinte:

Area de estudos da disciplina Tutorial-módulo 3-unidade 4, sę̧ão 4.3

Correto?

[MEDIADOR]: Olá, C...

Vejo que você está atento...

Quase acertou... módulo 4, unidade 4, seção 4.3...

Obrigado pela ajuda!!!!

[ALUNO]: Foi erro de teclado!

De qualquer forma, estamos prontos para colaborar!

Abraços!

[MEDIADOR]: Tenho certeza disso, $C$...

Estava brincando com você...

A colaboração éum aspecto relevante para a EAD...

\section{Ocorrência 8}

Olá, F!

Boa noite a todos...

Parece que o pessoal está ocupadão mesmo com o trabalho em equipe... só você postou hoje...

Caros alunos, não estou cobrando, não... ok? 
É só um comentário...

Sei que, na semana de Atividade em Equipe, discussōes gerais ficam um pouco esvaziadas mesmo.

Outro exemplo dessa estratégia é a forma como o professor realiza correções de eventuais erros dos alunos. $\mathrm{Na}$ fala seguinte, há uma preocupação em salvar a face da aluna que postou a mensagem na sala errada; o professor lança mão de um recurso poético, a personificação, "livrando" a aluna da responsabilidade pelo "erro".

Ocorrência 9

C, trouxe para esta discussão sua mensagem...

Ela estava triste eperdida lá na Hora do Recreio...

\section{Grupo C: Simule ou explicite reciprocidade}

Neste grupo de estratégias, verifica-se a preocupação do professor / mediador em se alinhar aos alunos. Associamos esse tipo à prática da alteridade, referida por Dotta e Giordan (2007), ao considerar a opinião dos alunos e suscitar a continuidade do diálogo.

Observemos uma das ocorrências em que o professor reconhece suas limitações ao tentar responder sobre dúvidas da área de matemática, que ele não domina, e recorre aos demais alunos, também professores, para tentar ajudá-lo:

Ocorrência 10

Xiiiiii...

Ge A, sou péssimo em Matemática...

Será que não há um professor da área de Exatas por ai não???

Outra evidência desse alinhamento é evidenciada quando o professor declara que também está aprendendo:

Ocorrência 11

Estou aprendendo intensamente... e aprender ébom demais...

Ocorrência 12

Bom dia, caros alunos...

[...]

Passei apenas para aprender um pouco mais... 


\section{Tabulação dos questionários}

\section{Questionários dos alunos}

$\mathrm{Na}$ tabulação das respostas dos alunos nos questionários, foi constatado que todos consideraram a atuação do professor / mediador satisfatória, assim como reconheceram que a atitude do professor influenciou sua motivação para o curso.

Ao responderem a parte aberta do questionário, os alunos elencaram algumas estratégias do professor / motivador que influenciaram sua participação positivamente, transcritas a seguir:

1) o nosso tutor, além de proativo, mostrou sensibilidade e muita inteligência no relacionamento interpessoal;

2) principalmente a linguagem, sua interação de forma positiva tanto nos assuntos do curso como nos assuntos informais. Tive um problema de ausência particular (nascimento da filha) e ele me incentivou a continuar.

3) a de sempre motivar o aluno nos momentos de dificuldade, facilitando o aprendizado e desmistificando que o ensino a distância não pode ter um acompanhamento cerrado ao aluno.

4) mensagens pessoais de incentivo; fórum de assuntos gerais (amenidades); informalidade no tratamento, aproximando o aluno do professor.

5) a estratégia do professor estar sempre postando mensagens na sala de aula e o fato de responder a todas as mensagens particulares enviadas influenciaram positivamente a minha participação;

6) mensagens incentivadoras; acompanhamento; elogios;

7) foi receptivo e compreensivo diante da situação que vivi na época (questões de saúde de meu marido) e manteve contato permanentemente com o grupo, estimulando a todos para que se mantivessem ligados ao curso.

Em relação às estratégias que influenciaram negativamente sua participação no curso, os alunos mencionaram as seguintes:

1) quando as respostas eram respostas prontas, não respondendo a minha dúvida específica;

2) algumas vezes, dúvidas de como realizar a tarefa eram confundidas como desconhecimento de manuseio do sistema Moodle, sendo o aluno direcionado ao suporte; 
3) confusão quanto às nossas identificações; orientaçóes incompletas ou equivocadas de determinadas atividades do curso;

4) recados e lembretes postados permanentemente, resposta rápida às nossas questôes e demandas.

Ao serem solicitados a reportar alguma situação que os tenha motivado ou desmotivado, foram apontadas as seguintes estratégias:

\section{Motivadoras:}

1) Nas primeiras tarefas, tive muita dificuldade. O professor demonstrou muita paciência, calma e sabedoria, pois solicitou um outro aluno do grupo para me auxiliar, além de auxiliar com o seu conhecimento.

2) O fato de ter recebido do professor uma orientação bem elaborada para a realização de uma das tarefas me motivou bastante.

\section{Desmotivadoras:}

1) Dificuldade em lidar com o ambiente virtual.

2) [...], na tarefa que era para criar uma sala no curso Mentoria, a minha dúvida foi confundida como falta de prática de manusear o sistema, sendo direcionado para o suporte. A dúvida persistiu por um bom tempo, atrapalhando o desenvolvimento do aprendizado do curso.

3) Grande quantidade de tarefas muito próximas.

4) Confusão quanto às nossas identificações; orientações incompletas ou equivocadas quanto à realização de determinadas tarefas do curso, o que me deixou muito confuso, já que apresento dificuldades em informática.

\section{Questionário do professor/mediador}

Mestre em Educação, o professor / mediador tem 20 anos de experiência no exercício docente, 7 dos quais em EAD. Além da experiência em tutoria em AVA, o professor declarou ter experiência em design instrucional.

O professor declara que é um apaixonado pela EAD, e isso o motiva; segundo ele, só consegue atuar bem se tiver paixão pelo que estiver fazendo. Demonstra autoconhecimento das principais características que o destacam como professor / mediador, as quais enumera: presença ativa, relacionamento afetivo, atenção e dedicação. Segundo o professor, esses traços são reconhecidos e valorizados pelos alunos; destaca ainda o trato com a atenção, o conhecimento dos alunos pelo nome e perfil como importantes na relação mediada por computador. 
Em relação ao cuidado que se deve ter com a linguagem, o professor enfatiza que a linguagem escrita é o principal, quando não o único, meio de comunicação com os alunos. Daí a necessidade de se ter um cuidado intenso com a linguagem. Aponta como principais qualidades da linguagem do bom professor em EAD a clareza, a objetividade, a concisão e a correção.

O professor é de opinião que um curso a distância não deve ter duração superior a quatro meses, pois a motivação do aluno tende a decrescer ao longo do curso. Sugere que, para minimizar a desmotivação e manter a participação, são necessárias novidades e atividades com desafios que o façam pensar.

\section{Considerações finais}

As interações entre professor / mediador e alunos na EAD são o canal que possibilita o desenvolvimento do processo educativo. As estratégias de polidez evidenciadas no discurso do professor / mediador demonstraram-se eficientes para promover a aprendizagem, conforme já haviam apontado Dotta e Giordan (2007), ao defenderem a importância do desenvolvimento da capacidade comunicativa do profissional para interaçóes verbais a distância. Dentro desse esquema, as tecnologias de informação e comunicação constituem-se em veículos importantes na comunicação entre professor / mediador e alunos nos dias atuais. Entretanto, esses recursos por si só não garantem o sucesso do processo educativo.

Dentre as estratégias de proteção da face positiva, elencadas na Teoria da Polidez de Brown e Levinson (1987), encontramos evidenciados no discurso do professor / mediador três tipos principais: (1) Tipo A: exagere o interesse, a aprovação e a simpatia pelo outro; (2) Tipo B: procure acordo; (3) simule ou explicite reciprocidade. Esses mecanismos resultaram em grande aceitação por parte dos alunos, que avaliaram o professor / mediador como um profissional sensível, positivo, incentivador, que, em última instância, facilitou a participação e a aprendizagem.

Constantino (2002) destacara que interações online exigem necessariamente um perfil de competência discursivo-didática do professor / mediador. A aceitação das iniciativas de polidez nessa situação de aprendizagem a distância sugere que é desejável que professores em formação sejam preparados com vistas a adquirir desde cedo o manejo dessas ferramentas linguísticopedagógicas. 


\section{Referências}

BAKHTIN, M. Marxismo e filosofia da linguagem. São Paulo: Hucitec, 1978.

BARBOSA, M. F. S. O. (Im)polidez em EAD. 2010. 172 f. Tese (Doutorado em Linguística). - Faculdade de Letras, Universidade Federal do Rio de Janeiro, Rio de Janeiro, 2010.

BROWN, P.; LEVINSON, S. Politeness: some universals in language usage. Cambridge: CUP, 1987.

CONSTANTINO, G. D. Presenza vitale contro presenza virtuale: studio contrastivo dei modi strategico-discorsivi della interazione didattica. In: BANZATO, M. (Org.). Apprendere in rete. Torino: UTET, 2002. p. 218-262.

DAVIS, B. H.; BREWER, J. P. Electronic discourse: linguistic individuals in virtual space. New York: SUNY, 1997.

DOTTA, S; GIORDAN, M. Formação a distância de educadores para o diálogo virtual em serviços de tutoria on-line. In: SIMPÓSIO BRASILEIRO DE INFORMÁTICA NA EDUCAÇÃO, 17. 2006, Anais... Brasília: Sociedade Brasileira de Computação, 2006.

DOTTA, S; GIORDAN, M. Formação de professores para interação em processos de tutoria pela internet. SIMPÓSIO DE INFORMÁTICA EDUCATIVA, SIIE, 9, Porto, Portugal, 14 a 16 nov. 2007.

DOTTA, S; GIORDAN, M. Estudo das interações mediadas por um serviço de tutoria pela Internet. Linguagem \& Ensino. Pelotas, v. 11, n. 1, p. 127-143, jan/ jun. 2008.

ERICKSON, F. Ethnographic Description. In: AMMON, U; DITTMAR, N.; MATTHEIER, K.J.; TRUDGILL, P. (Ed.). Sociolinguistics. 2. Berlin/New York: Walter de Gruyter, 1988. p. 1081 -1095.

FREIRE, P. Pedagogia do Oprimido. Rio de Janeiro: Paz e Terra, 1983.

FREIRE, Paulo. Pedagogia do Oprimido. 42. ed. Rio de Janeiro: Paz e Terra, 2005.

GAGNÉ, R. M. Las condiciones del aprendizaje. México: Trillas, 1985.

GARCIA ARETIO, L. La educación a distancia: de la teoría a la práctica. Barcelona: Ariel Educación, 2001. 328 p.

GIORDAN, M. Uma perspectiva sociocultural para os estudos sobre elaboração de significados em situaçōes de uso do computador na Educação em Ciências. 2006. 315f. Tese (Livre Docência) - Faculdade de Educação, Universidade de São Paulo, São Paulo, 2006. 
GRAHAM, S. L. Disagreeing to agree: conflict, (im)politeness and identity in a computer-mediated community. Journal of Pragmatics, v. 39, Issue 4, p. $742-$ 759, April 2007. Disponível em: <http://www.sciencedirect.com>. Acesso em: 19 maio 2010.

HYMES, D. Competence and performance in linguistic theory. In: HUXLEY, R.; INGRAM, E. (Ed.). New York: Academic Press, 1971. p. 3-23.

MATTHEIER, K. (Org.). Sociolinguistics: an international Handbook of Science of Language and Society. Berlin/Nova York: Walter de Gruyter, 2006. p. 1081-1095.

MERINO, A. P.; TAPIA, J. A. Motivar en el aula. Madri: Servicio de Publicaciones de la Universidad Autônoma, 1990.

MORTIMER, E. F.; SCOTT, P. Atividade discursiva nas salas de aula de ciências: uma ferramenta sociocultural para analisar e planejar o ensino. Investigaçôes em Ensino de Ciências, Porto Alegre, v. 7, n. 3, p. 283-306, 2002. Disponível em: $<$ http://www.if.ufrgs.br/public/ensino/revista.htm>. Acesso em: 18 maio 2010. SPENCER-OATEY, H.; RUHI, A. Identity, face and impoliteness. Journal of Pragmatics, v. 39, n. 4, p. 635-638, 2007.

TAPIA, J. A.; FITA, E. C. A motivação em sala de aula. O que é, como se faz. São Paulo: Ediçōes Loyola, 1999.

VYGOTSKY, L. S. Paidologia del adolescente. In: Obras Escogidas. Tomo IV, Madrid: Visor Distribuiciones, 1996. 427 p.

WELLS, G. Dialogic inquiry: toward a sociocultural practice and theory of education. Cambridge: CUP, 1999. 372 p.

Recebido em 23 de junho de 2010. Aprovado em 13 de agosto de 2010. 